\title{
Antibiotic therapy augments the efficacy of gemcitabine-containing regimens for advanced cancer: a retrospective study
}

This article was published in the following Dove Press journal: Cancer Management and Research

\author{
Hiroo Imai' \\ Ken Saijo' \\ Keigo Komine' \\ Yasufumi Otsuki ${ }^{2}$ \\ Kota Ohuchi' \\ Yuko Sato' \\ Akira Okita ${ }^{2}$ \\ Masahiro Takahashi ${ }^{1}$ \\ Shin Takahashi ${ }^{2}$ \\ Hidekazu Shirota' \\ Masanobu Takahashi ${ }^{2}$ \\ Chikashi Ishioka ${ }^{2}$ \\ 'Department of Medical Oncology, \\ Tohoku University Hospital, Sendai, \\ Japan; ${ }^{2}$ Department of Clinical Oncology, \\ Institute of Developing, Aging and \\ Cancer, Tohoku University, Sendai, Japan
}

Correspondence: Chikashi Ishioka Department of Medical Oncology, Tohoku University Hospital, 4-I, Seiryo-machi,

Aobaku, Sendai $980-8575$, Japan

Tel +8I 227178543

Fax +8I 227178548

Email chikashi@tohoku.ac.jp
Background: The addition of antibiotics reportedly augments the efficacy of gemcitabine (GEM) in tumor-bearing mice. However, whether this phenomenon is also observed in cancer patients remains unclear. In the present study, we aimed to assess whether antibiotics for treatment or prevention of infection augments treatment efficacies of GEM-containing regimens in patients with any type of cancer.

Methods: Medical records of patients diagnosed with cancer histopathologically and treated with GEM-containing regimens $(n=169)$ were retrospectively reviewed. Patients were assigned into two groups: antibiotics-untreated group (patients who were treated with GEM-containing regimens but without antibiotics) and antibiotics-treated group (patients who were treated with GEM-containing regimens plus antibiotics). Response rates, progression-free survival (PFS) time, and overall survival (OS) time were analyzed for each group. Results: The response rates of the antibiotics-untreated and antibiotics-treated groups with GEMcontaining regimens were $15.1 \%$ and $27.6 \%$, respectively. The median PFS times of the antibioticsuntreated and antibiotics-treated groups were 2.5 (95\% CI: 1.86-3.73) and 4.9 (95\% CI: 3.47-6.0) months, respectively. The median OS times of the antibiotics-untreated and antibiotics-treated groups were 7.53 (95\% CI: 5.63-9.57) months and 13.83 (95\% CI: 10.83-16.43) months, respectively.

Conclusion: The addition of antibiotics augments the treatment efficacies of GEM-containing regimens, and it may be a potential therapeutic option to improve treatment efficacies of GEM-containing regimens in patients with advanced cancer.

Keywords: antibiotics, bacteria, gemcitabine, multivariate analysis, univariate analysis

\section{Background}

Gemcitabine (GEM) is one of the anticancer drugs that is often used for patients with advanced cancer. ${ }^{1}$ GEM-containing regimens are used for patients with pancreatic cancer, biliary tract cancer, lung cancer, sarcoma, urothelial cancer, or breast cancer. ${ }^{2-7}$ Literature is limited on the responses of GEM-containing regimens in patients with advanced cancers ${ }^{5,8-10}$; this necessitates the improvement of treatment efficacies of GEM-containing regimens in patients with advanced cancers.

A previous study reported that GEM $\left(2^{\prime}, 2^{\prime}\right.$-difluorodeoxycytidine $)$ is metabolized into an inactive metabolite $2,2^{\prime}$-difluorodeoxyuridine by various microbes that express a long isoform of the bacterial enzyme cytidine deaminase $\left(\mathrm{CDD}_{\mathrm{L}}\right) \cdot{ }^{11}$ In other previous reports, the treatment of tumor-bearing mice with antibiotics eradicates the bacteria from the tumor tissue and consequently increases the concentration of GEM in the tumor tissue. ${ }^{12}$ 
Increased concentration of GEM in the tumor tissue resulted in robust tumor regression, whereas the mouse not treated with GEM did not exhibit tumor regression. ${ }^{12}$ Moreover, various bacteria expressed $\mathrm{CDD}_{\mathrm{L}}$ in human pancreatic cancer tissue, and these bacteria potently conferred the resistance of GEM in the cancer cell line in vitro. ${ }^{12}$ Therefore, the bacteria that express $\mathrm{CDD}_{\mathrm{L}}$ in tumor tissue may be related to the low treatment efficacies of GEM in human and that the addition of antibiotics to a regimen-containing GEM would augment its efficacy. However, no previous report had examined whether the addition of antibiotics augments the treatment efficacy of GEM in patients with advanced cancer.

In this study, we tried to assess whether antibiotics given for treatment or prevention of infection augment the treatment efficacy of GEM-containing regimens in patients with various types of advanced cancers.

\section{Methods}

\section{Patients}

Medical records of patients who were diagnosed with cancer histopathologically and were treated with GEM-containing regimens $(n=169)$ were retrospectively reviewed at the Department of Medical Oncology, Tohoku University Hospital from 2006 to 2018. Patients with advanced stage of pancreatic cancer, biliary tract cancer, duodenal cancer, cancer of unknown primary, neuroendocrine carcinoma, sarcoma, and urinary bladder cancer were included in this study. Patients with stage III or stage IV cancers were included in the antibiotics-untreated and antibiotics-treated group. Proportions of patients with stage III or IV cancer were similar between the two groups.

Inclusion criteria of this study included: 1) patients who had been histologically confirmed carcinoma or sarcoma; 2) patients who had unresectable cancer (or sarcoma) or metastatic lesion; 3) patients who had been treated with at least one course of GEM-containing regimen; 4) patients who had at least one measurable cancer (or sarcoma) lesion; 5) patient in whom the treatment efficacies of GEM-containing regimen in cancer (or sarcoma) had been assessed by computed tomography (CT) at least once. In all, there were 196 patients who met the inclusion criteria. Patients who did not meet inclusion criteria were all excluded from the analyses in this study.

\section{Treatment methods}

The doses and schedules of GEM treatment in this study were as follows. GEM alone (plus erlotinib): GEM $1000 \mathrm{mg} / \mathrm{m}^{2}$, days 1, 8 and 15 (erlotinib $100 \mathrm{mg} /$ body, days 1-28) every 4 weeks; GEM plus nanoparticle albumin binding paclitaxel (nabPTX): GEM $1000 \mathrm{mg} / \mathrm{m}^{2}$, nabPTX $125 \mathrm{mg} / \mathrm{m}^{2}$, days 1 , 8,15 , every 4 weeks; GEM plus cisplatin (plus $\mathrm{S}-1$ ): GEM $1000 \mathrm{mg} / \mathrm{m}^{2}$, cisplatin $25 \mathrm{mg} / \mathrm{m}^{2}$, days $1,8\left(\mathrm{~S}-180 \mathrm{mg} / \mathrm{m}^{2}\right.$, days $1-14$, every 3 weeks; GEM plus docetaxel: GEM 900 $\mathrm{mg} / \mathrm{m}^{2}$, day 1,8 , docetaxel $70 \mathrm{mg} / \mathrm{m}^{2}$ day 8 , every 3 weeks.

Antibiotics were administered according to the drug attachment (e.g., levofloxacin hydrate: oral administration, $500 \mathrm{mg} /$ body/day; cefdinir: oral administration, $300 \mathrm{mg} /$ body/day; meropenem hydrate: intravenous administration, 0.5-1 g/body/day.) The administration period of antibiotics was determined by the chief physician of each patient.

\section{Evaluation}

Patients were assigned into two groups. The first was the antibiotics-treated group where patients had been treated with antibiotics from the start of the GEM-containing regimen to the first imaging evaluation of the efficacy of GEMcontaining regimen using CT (antibiotics-treated group). The other group was the antibiotics-untreated group where patients had not been treated with antibiotics from the start of the GEM-containing regimen to the first CT evaluation of the efficacy of the GEM-containing regimen.

Responses were assessed using Response Criteria in Solid Tumor version 1.0. ${ }^{13}$ The rates of complete response (CR; all signs of cancer disappeared by treatment with GEM-containing regimen) and partial response (PR; defined as $a \geq 30 \%$ reduction in the diameter of measurable lesions on $\mathrm{CT}$ ) were combined and defined as the response rate. $\mathrm{CR}, \mathrm{PR}$, and stable disease (defined as a $<30 \%$ reduction and a $<20 \%$ increase in the diameter of measurable lesions as shown on $\mathrm{CT}$ ) rates were combined, and these rates were defined as the disease control rate. In this study, the relative dose intensity of GEM was defined as the ratio of the total actual dose of GEM delivered to patients to the planned dose of GEM. All toxicities were reviewed from medical records and were evaluated according to the Common Terminology Criteria for Adverse Events version 4.0. ${ }^{14}$

\section{Statistical analysis}

The median progression-free survival (PFS) time and median overall survival (OS) time were calculated using the Kaplan-Meier method. $P$-values of the response rate and disease control rate were based on Fisher's exact test. All statistical analyses including univariate analysis, multivariate analysis, Pearson's chi-squared test, and Wilcoxon Mann-Whitney test were performed using JMP $^{\circledR} 11$ 
(SAS Institute Inc., Cary, NC, USA). All differences were regarded as statistically significant when $P<0.05$.

\section{Results}

\section{Patient characteristics}

We identified 169 patients who were treated with GEMcontaining regimen (antibiotics-untreated group $=93$; antibiotics-treated group $=76$ ). Patient characteristics are presented in Table 1. Approximately, $80 \%$ of the subjects had pancreatic or biliary tract cancer. Relative dose intensities of GEM in the antibiotics-untreated and antibiotics-treated groups were $81.1 \%$ and $78.9 \%$, respectively. Proportions of sex, previous surgery, types of GEM-containing regimens were similar between the two groups.

\section{Efficacies of GEM-containing regimens}

We calculated the response rate of patients to GEM-containing regimens. As shown in Table 2, the response rates in the antibiotics-untreated and antibiotics-treated groups by GEM-containing regimens were $15.1 \%$ and $27.6 \%$, respectively. Disease control rates in the antibioticsuntreated and antibiotics-treated groups by GEM-containing regimens were $51.6 \%$ and $72.4 \%$, respectively. The response and disease control rates were significantly higher in the antibiotics-treated group than in the antibiotics-untreated group.

As shown in Figure 1, the median PFS times of the antibiotics-untreated and antibiotics-treated groups were 2.5 (95\% CI: 1.86-3.73) days and 4.93 (95\% CI: $3.47-$ 6.0) months, respectively. The median PFS rate was significantly higher in the antibiotics-treated group than in the antibiotics-untreated group $(P<0.0001$, log-rank test). As shown in Figure 2, the median OS times of the antibioticsuntreated and antibiotics-treated groups were $7.53(95 \%$ CI: 5.63-9.57) months and 13.83 (95\% CI: 10.83-16.43) months, respectively. The median OS rate was significantly higher in the antibiotics-treated group than in the antibiotics-untreated group $(P<0.0001, \log$-rank test). The median PFS and the median OS of the patients with each cancer type in antibiotics-treated group and antibioticsuntreated group were shown in Table S1. In all cancer types, both the median PFS and the median OS of antibiotics-treated group were longer than these of antibioticsuntreated group. Especially, in pancreatic cancer, both the median PFS and the median OS of the antibiotics-treated group were significantly longer than those of the antibiotics-untreated group. In sarcoma, the median OS of the antibiotics-treated group was significantly longer than that of antibiotics-untreated group. Original data of each patient were shown in Table S2.

\section{Toxicities}

Toxicities by GEM-containing regimens in the antibiotics-untreated and antibiotics-treated group are shown in Table 3. The proportions of patients with severe leukopenia and neutropenia by GEM-containing regimens in the antibiotics-treated group were higher than those in the antibiotics-untreated group. Patients with a febrile neutropenia were included only in the antibiotics-treated group. The incidence rates of anemia, thrombocytopenia, and elevated aspartate aminotransferase (AST) or alanine aminotransferase (ALT) level were similar between the two groups. No patients died from adverse events of GEM-containing regimens.

\section{Univariate and multivariate analyses}

We performed univariate and multivariate analyses for the relationship between the responses to GEM-containing regimens and patient background or a severe neutropenia by GEM-containing regimens. Results of univariate and multivariate analyses are shown in Table 4. We found statistically significant correlations between the response by GEM-containing regimens and antibiotic treatment (univariate analysis: $P=0.0305$, multivariate analysis: $P=0.0314$ ). Seven factors (age, sex, severe neutropenia, operation history, tumor stage, cancer primary site, and type of GEM-containing regimens) analyzed did not significantly correlate with the response of GEM-containing regimens.

\section{Discussion}

A previous study ${ }^{12}$ revealed that the antitumor efficacy of GEM was augmented by the addition of antibiotics in tumor-bearing mice compared to the antitumor efficacy of GEM alone. However, no previous report has demonstrated the augmentation of antitumor efficacy of GEM by addition of antibiotics in cancer patients. In this study, we observed that the treatment efficacy of GEM-containing regimens with antibiotics was augmented compared to that of GEM-containing regimens without antibiotics in patients with various types of advanced cancer. In all cancer type in this study, there had been tendency that both the median PFS and the median OS in the antibiotics-treated group were longer than these of antibioticsuntreated group. 
Table I Patient characteristics

\begin{tabular}{|c|c|c|c|}
\hline & Antibiotics-untreated group & Antibiotics-treated group & $P$-value \\
\hline Number & 93 & 76 & \\
\hline Sex $(\%)$ & & & 0.785 \\
\hline Male & $56(60.2)$ & $46(60.5)$ & \\
\hline Female & $37(39.8)$ & $30(39.5)$ & \\
\hline Mean age (range) & $63.9(29-80)$ & $63.0(31-84)$ & \\
\hline Cancer type (\%) & & & 0.346 \\
\hline Pancreatic cancer & $60(64.5)$ & $45(59.2)$ & \\
\hline Biliary tract cancer & $16(17.2)$ & $18(23.7)$ & \\
\hline Sarcoma & $9(9.7)$ & $9(11.8)$ & \\
\hline CUP & $3(3.2)$ & $2(2.6)$ & \\
\hline Duodenal cancer & $3(3.2)$ & $\mathrm{I}(\mathrm{I} .3)$ & \\
\hline Neuroendocrine carcinoma & $\mathrm{I}(\mathrm{I} . \mathrm{I})$ & $0(0.0)$ & \\
\hline Breast cancer & $\mathrm{I}(\mathrm{I} . \mathrm{I})$ & $0(0.0)$ & \\
\hline Ulinary bladder cancer & $0(0.0)$ & $\mathrm{I}(\mathrm{I} .3)$ & \\
\hline Tumor stage & & & 0.891 \\
\hline III & $8(8.6)$ & $7(9.2)$ & \\
\hline IV & $85(91.4)$ & $69(90.8)$ & \\
\hline Operation history (\%) & & & 0.755 \\
\hline+ & $23(24.7)$ & $23(30.3)$ & \\
\hline- & $70(75.3)$ & $53(69.7)$ & \\
\hline GEM including regimen (\%) & & & 0.412 \\
\hline GEM alone & $48(52.1)$ & $34(44.7)$ & \\
\hline GEM plus nabPTX & $20(22.9)$ & $20(26.3)$ & \\
\hline GEM plus cisplatin & $12(12.5)$ & $12(15.8)$ & \\
\hline GEM plus docetaxel & $9(9.4)$ & $9(11.8)$ & \\
\hline GEM plus cisplatin plus S-I & $3(2.1)$ & $0(0.0)$ & \\
\hline GEM plus elrotinib & $\mathrm{I}(\mathrm{I} .0)$ & $\mathrm{I}(\mathrm{I} .3)$ & \\
\hline Relative dose intensity of GEM (\%) & 81.1 & 78.9 & 0.788 \\
\hline \multicolumn{4}{|l|}{ Treated antibiotics } \\
\hline New quinolone & & $38(50.0)$ & \\
\hline Second-generation cephem & & $3(3.9)$ & \\
\hline Third-generation cephem & & $15(19.7)$ & \\
\hline Fourth-generation cephem & & $13(17.1)$ & \\
\hline Carbapenem & & $3(3.9)$ & \\
\hline$\beta$-Lactamase inhibitor & & $2(2.6)$ & \\
\hline Penicillin & & $\mathrm{I}(\mathrm{I} .3)$ & \\
\hline \multicolumn{4}{|l|}{ Reason of antibiotics treatment } \\
\hline Because of infection & & $16(21.1)$ & \\
\hline To prevent infection & & 60 (78.9) & \\
\hline
\end{tabular}

Note: $P$-values were calculated using chi-squared test or Wilcoxon or Mann-Whitney test.

Abbreviations: CUP, cancer of unknown primary; nabPTX, nanoparticle albumin binding paclitaxel; GEM, gemcitabine.

A previous study ${ }^{12}$ demonstrated that antibiotics therapy (150 mg/kg of new quinolone) even for 2 days significantly removed bacteria from the tumor tissue in mice and consequently reduced the $\mathrm{CDD}_{\mathrm{L}}$ from bacteria. The reduction of $\mathrm{CDD}_{\mathrm{L}}$ resulted in the low metabolism of GEM by bacteria and the high concentration of GEM in the tumor tissue. ${ }^{12}$ The dosage of antibiotics in that study ${ }^{12}$ was similar to those usually used in patients in clinical 
Table 2 Response rate of gemcitabine-containing regimens

\begin{tabular}{|l|l|l|l|l|l|}
\hline & CR & PR & SD & PD & RR (\%) \\
\hline Antibiotics-untreated group & 0 & 14 & 34 & 45 & 15.1 \\
Antibiotics-treated group & 0 & 21 & 34 & 21 & 27.6 \\
\hline
\end{tabular}

Notes: $P$-value of response rate between two groups. Antibiotics-untreated group vs antibiotics-treated group $P=0.0356$. $P$-value of disease control rate between each group. Antibiotics-untreated group vs antibiotics-treated group $P=0.007$.

Abbreviations: $C R$, complete response; DCR, disease control rate; PD, progression disease; PR, partial response; RR, response rate; SD, stable didease.

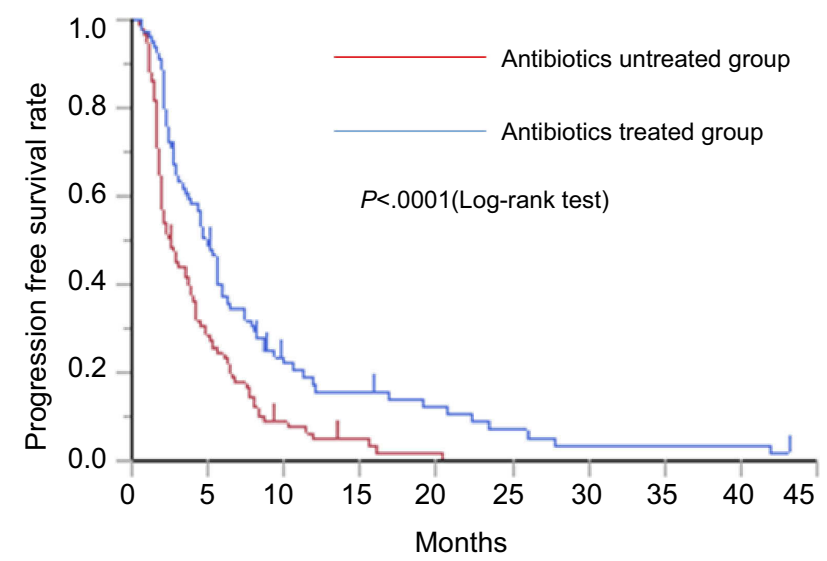

Figure I Kaplan-Meier curve of the PFS rate in the antibiotics-untreated group and antibiotics-treated group.

Abbreviation: PFS, progression-free survival.

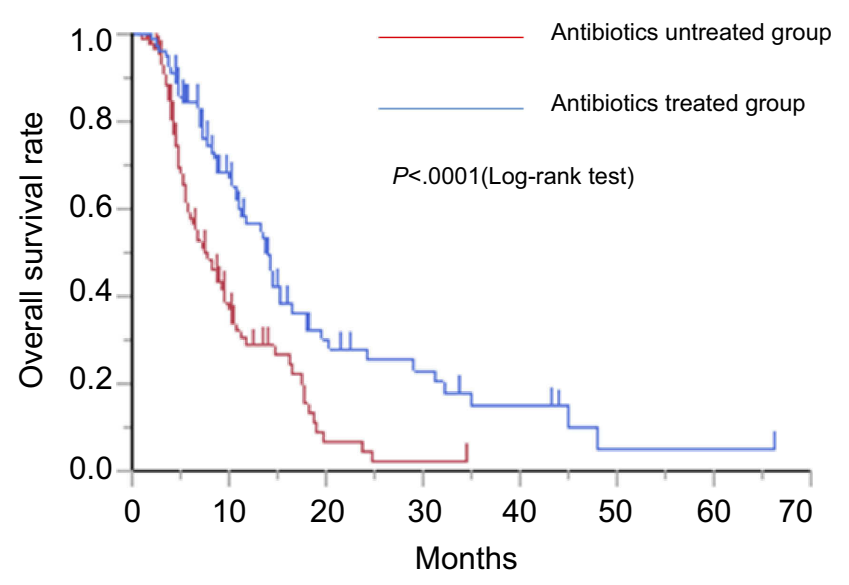

Figure 2 Kaplan-Meier curve of the OS rate with the antibiotics-untreated group and antibiotics-treated group.

Abbreviation: OS, overall survival

practice. In the present study, all antibiotics were given in doses similar to those in clinical practice. In this study, as we did not investigate the amount of bacteria in the cancer tissue from patients, it is unclear whether bacteria were sufficiently removed from the tumor tissue by the antibiotics therapy. However, based on a previous study, ${ }^{12}$ the dosage of antibiotics used in the present study appeared to be sufficient to reduce the bacteria from the tumor tissue.
Table 3 Severe (grade 3 or 4) toxicities by gemcitabine-containing regimens

\begin{tabular}{|l|l|l|}
\hline & $\begin{array}{l}\text { Antibiotics- } \\
\text { untreated group } \\
(\mathbf{n = 9 3 )}\end{array}$ & $\begin{array}{l}\text { Antibiotics- } \\
\text { treated group } \\
(\mathbf{n = 7 6 )}\end{array}$ \\
\hline Leukopenia & $14(15.1)$ & $36(47.4)$ \\
Neutropenia & $27(29.0)$ & $42(55.3)$ \\
Anemia & $15(16.1)$ & $12(15.8)$ \\
Thrombocytopenia & $10(10.7)$ & $2(9.2)$ \\
Febrile neutropenia & $0(0.0)$ & $6(7.6)$ \\
Elevated AST/ALT & $7(7.5)$ & $6)$ \\
\hline
\end{tabular}

Abbreviations: ALT, alanine aminotransferase; AST, aspartate aminotransferase.

Moreover, in the present study, the augmentation of the treatment efficacy of GEM-containing regimen by the addition of antibiotics might be attributable to the removal of bacteria from the cancer tissue, which consequently increased the concentration of GEM in cancer tissues.

In this study, the incidence rates of severe leukopenia and neutropenia by GEM-containing regimens were higher in the antibiotics-treated group than in the antibioticsuntreated group. Usually, patients who have grade 3 or 4 of leucopenia or neutropenia during chemotherapy are treated with antibiotics to prevent infections. ${ }^{15}$ Therefore, it is inevitable that the antibiotics-treated group includes patients with severe leukopenia or neutropenia. The proportions of anemia, thrombocytopenia, or elevated AST or ALT level were similar between two groups, suggesting that the addition of antibiotics do not increase the adverse effects by GEM-containing regimens.

Alteration of gut microbiota by antibiotics influenced the efficacies and toxicities of irinotecan as irinotecan metabolism was affected by bacteria in mice gut. ${ }^{16}$ Antibiotic treatment might change the gut microbiota in patients in the present study and might influence the metabolism of GEM by the bacteria in the gut similar to that in a previous report. ${ }^{16}$ These changes might elevate the blood concentration of GEM, resulting in higher toxicities with GEM-containing regimen in the antibiotics-treated group. However, the incidence rates of anemia, thrombocytopenia, and elevated AST 
Table 4 Univariate and multivariate analyses for the relationship between the response to the gemcitabine-containing regimens and patients' background or toxicity by gemcitabine-containing regimens

\begin{tabular}{|c|c|c|c|c|}
\hline & \multirow[t]{2}{*}{ n (\%) } & \multirow{2}{*}{$\begin{array}{l}\text { Univariete analysis } \\
P \text {-value }\end{array}$} & \multicolumn{2}{|l|}{ Multivariate analysis } \\
\hline & & & OR $(95 \% \mathrm{Cl})$ & $P$-value \\
\hline \multicolumn{5}{|l|}{ Sex } \\
\hline Male & $102(60.3)$ & 0.5621 & $1.39(0.632-3.058)$ & 0.4129 \\
\hline Female & $67(39.7)$ & & & \\
\hline \multicolumn{5}{|l|}{ Age } \\
\hline$\geqq 65$ & $90(53.3)$ & 0.4144 & $1.733(0.765-3.926)$ & 0.1877 \\
\hline$<65$ & $79(46.7)$ & & & \\
\hline \multicolumn{5}{|l|}{ Antibiotics } \\
\hline Untreated & $93(55.0)$ & 0.0305 & $2.444(1.083-5.519)$ & 0.0314 \\
\hline Treated & $76(45.0)$ & & & \\
\hline \multicolumn{5}{|l|}{ Severe (grade 3 or 4 ) neutropenia } \\
\hline Negative & $110(65.1)$ & 0.6975 & $0.696(0.293-1.65 I)$ & 0.4103 \\
\hline Positive & 59 (34.9) & & & \\
\hline \multicolumn{5}{|l|}{ Operaion history } \\
\hline Negative & $123(72.8)$ & 0.1148 & $0.364(0.129-1.033)$ & 0.0577 \\
\hline Positive & $46(27.2)$ & & & \\
\hline \multicolumn{5}{|l|}{ Tumor stage } \\
\hline III & $15(8.9)$ & 0.4360 & $2.321(0.473-11.392)$ & 0.2995 \\
\hline IV & I54 (9I.I) & & & \\
\hline \multicolumn{5}{|l|}{ Cancer type } \\
\hline Pancreatic cancer & $105(62.1)$ & 0.7799 & $0.919(0.383-2.205)$ & 0.8500 \\
\hline Other cancers & $64(37.9)$ & & & \\
\hline \multicolumn{5}{|l|}{ Type of GEM-containing regimen } \\
\hline GEM alone & $82(48.5)$ & 0.0700 & $1.997(0.842-4.738)$ & 0.1165 \\
\hline Combination of GEM and other anticancer drug & $87(51.5)$ & & & \\
\hline
\end{tabular}

Note: $P$-values were analyzed using Pearson's chi-square test.

Abbreviation: GEM, gemcitabine.

or ALT level were similar between the two groups in the present study. Therefore, it is assumed that the general concentration of GEM is not elevated but elevated locally in the tumor tissue.

The univariate and multivariate analyses in the present study revealed that antibiotic treatment significantly correlated to the response of GEM-containing regimens. These results suggest that the addition of antibiotics was the cause of improvement of the treatment of efficacies of GEM-containing regimens.

This study has some limitations. First, this study has a retrospective design. Second, the number of patients is relatively small. Third, several previous studies have reported the influence of antibiotics on the activity of cytochrome P450 (CYP) or on the induction of CYP in humans. $^{17-20}$ The change in CYP activity or in CYP induction by antibiotics influences the metabolisms of other anticancer drugs. ${ }^{21-24}$ The metabolism of GEM is possibly modified by CYP mediated by antibiotics. However, no study has reported about GEM metabolism by CYP. Therefore, it is still uncertain whether the blood concentration of GEM changes via CYP. Fourth, the timing and duration of antibiotic treatment during GEM-containing regimens varied with each patient. However, the background of the two groups was very similar, except that antibiotics were added to GEM-containing regimens only in the antibiotics-treated group. Thus, the improvement of treatment efficacy of GEM-containing regimens might be attributable to the addition of antibiotics to patients in the antibiotics-treated group. Forth, although there are several mechanisms modulating the sensitivities of GEM in cancer patients, we did not investigate the 
GEM resistant mechanisms in patients in this study. It has been reported that the dysregulation of proteins participating in GEM metabolism pathway or the high expression of GEM efflux pump is the mechanisms responsible for GEM resistance. ${ }^{25-27}$ Moreover, it was also reported that $B R C A 1$ associated protein 1 gene (BAP1) mutation is responsible for the sensitivity of GEM in patients with malignant mesothelioma. ${ }^{28}$ To investigate whether these resistant mechanisms influence on efficacies of the antibiotics and GEM-containing regimen combination therapy or not is needed.

\section{Conclusion}

The addition of antibiotics to GEM-containing regimens might be a potential therapeutic option to improve treatment efficacies of GEM-containing regimens in patients with advanced cancer.

\section{Ethics approval and consent to participate}

This study protocol was approved by the ethics committee of Tohoku University Hospital. The ethics committee of Tohoku University Hospital has permitted to conduct retrospective studies without consent statements by patients (opt-out system). All data in the current study had no personal identifiers and were kept confidential.

\section{Abbreviations}

ALT, alanine aminotransferase; AST, aspartate aminotransferase; $\mathrm{CDD}_{\mathrm{L}}$, long isoform of the bacterial enzyme cytidine deaminase; $\mathrm{CR}$, complete response; $\mathrm{CT}$, computed tomography; CYP, cytochrome P450; OS, overall survival; PFS, progression-free survival; PR, partial response.

\section{Author contributions}

Hiroo Imai designed the study and wrote the initial draft of the manuscript. Chikashi Ishioka is the corresponding author and contributed to analysis and interpretation of data and assisted in the preparation of the manuscript. All other authors have contributed to data collection and interpretation and critically reviewed the manuscript. All authors approved the final version of the manuscript and agree to be accountable for all aspects of the work in ensuring that questions related to the accuracy or integrity of any part of the work are appropriately investigated and resolved.

\section{Disclosure}

Chikashi Ishioka received research funding from the Tokyo Cooperative Oncology Group. Chikashi Ishioka also received contributions from Chugai Pharmaceutical, Ono Pharmaceutical, MSD, Pfizer, AstraZeneca, Bristol-Myers Squibb, Janssen Pharmaceutical, Taiho Pharmaceutical, Daiichi Sankyo Company, Limited, and Takeda Pharmaceutical. Chikashi Ishioka is a representative of Tohoku Clinical Oncology Research and Education Society, a specified nonprofit corporation. Dr Masahiro Takahashi reports grants from Ono Pharmaceutical, outside the submitted work. The authors report no other conflicts of interest in this work.

\section{References}

1. Lund B, Kristjansen PE, Hansen HH. Clinical and preclinical activity of 2',2'-difluorodeoxycytidine (gemcitabine). Cancer Treat Rev. 1993;19(1):45-55.

2. Kamisawa T, Wood LD, Itoi T, Takaori K. Pancreatic cancer. Lancet (London, England). 2016;388(10039):73-85. doi:10.1016/S01406736(16)00141-0

3. Gruenberger B, Schueller J, Heubrandtner U, et al. Cetuximab, gemcitabine, and oxaliplatin in patients with unresectable advanced or metastatic biliary tract cancer: a phase 2 study. Lancet Oncol. 2010;11(12):1142-1148. doi:10.1016/S1470-2045(10)70247-3

4. Wu YL, Zhou C, Hu CP, et al. Afatinib versus cisplatin plus gemcitabine for first-line treatment of Asian patients with advanced nonsmall-cell lung cancer harbouring EGFR mutations (LUX-Lung 6): an open-label, randomised phase 3 trial. Lancet Oncol. 2014;15 (2):213-222. doi:10.1016/S1470-2045(13)70604-1

5. Seddon B, Strauss SJ, Whelan J, et al. Gemcitabine and docetaxel versus doxorubicin as first-line treatment in previously untreated advanced unresectable or metastatic soft-tissue sarcomas (GeDDiS): a randomised controlled phase 3 trial. Lancet Oncol. 2017;18 (10):1397-1410. doi:10.1016/S1470-2045(17)30622-8

6. Naiki T, Iida K, Etani T, et al. Gemcitabine and docetaxel as secondline chemotherapy in elderly patients with metastatic urothelial carcinoma: a retrospective analysis. Cancer Manag Res. 2018;10:36693677. doi:10.2147/CMAR.S172913

7. Zhang J, Lin Y, Sun XJ, et al. Biomarker assessment of the CBCSG006 trial: a randomized phase III trial of cisplatin plus gemcitabine compared with paclitaxel plus gemcitabine as firstline therapy for patients with metastatic triple-negative breast cancer. Ann Oncol. 2018;29(8):1741-1747. doi:10.1093/annonc/ mdy209

8. Ramanathan RK, Goldstein D, Korn RL, et al. Positron emission tomography response evaluation from a randomized phase III trial of weekly nab-paclitaxel plus gemcitabine versus gemcitabine alone for patients with metastatic adenocarcinoma of the pancreas. Ann Oncol. 2016;27(4):648-653. doi:10.1093/annonc/ mdw020

9. Lee JK, Capanu M, O’Reilly EM, et al. A phase II study of gemcitabine and cisplatin plus sorafenib in patients with advanced biliary adenocarcinomas. Br J Cancer. 2013;109(4):915-919. doi:10.1038/ bjc.2013.432

10. Katakami N, Felip E, Spigel DR, et al. A randomized, open-label, multicenter, phase 3 study to compare the efficacy and safety of eribulin to treatment of physician's choice in patients with advanced non-small cell lung cancer. Ann Oncol. 2017;28(9):2241-2247. doi:10.1093/annonc/mdx284 
11. Baker JA, Wickremsinhe ER, Li CH, et al. Pharmacogenomics of gemcitabine metabolism: functional analysis of genetic variants in cytidine deaminase and deoxycytidine kinase. Drug Metab Dispos. 2013;41(3):541-545. doi:10.1124/dmd.112.048769

12. Geller LT, Barzily-Rokni M, Danino T, et al. Potential role of intratumor bacteria in mediating tumor resistance to the chemotherapeutic drug gemcitabine. Science (New York, NY). 2017;357(6356):11561160. doi:10.1126/science.aah5043

13. Therasse P, Arbuck SG, Eisenhauer EA, et al. New guidelines to evaluate the response to treatment in solid tumors. European Organization for Research and Treatment of Cancer, National Cancer Institute of the United States, National Cancer Institute of Canada. J Natl Cancer Inst. 2000;92(3):205-216. doi:10.1093/jnci/ 92.3.205

14. Tobinai K, Kohno A, Shimada Y, et al. Toxicity grading criteria of the Japan Clinical Oncology Group. The clinical trial review committee of the Japan Clinical Oncology Group. Jpn J Clin Oncol. 1993;23(4):250-257.

15. Freifeld AG, Bow EJ, Sepkowitz KA, et al. Clinical practice guideline for the use of antimicrobial agents in neutropenic patients with cancer: 2010 update by the infectious diseases society of america. Clin Infect Dis. 2011;52(4):e56-e93. doi:10.1093/cid/cir073

16. Wallace $\mathrm{BD}$, Wang $\mathrm{H}$, Lane $\mathrm{KT}$, et al. Alleviating cancer drug toxicity by inhibiting a bacterial enzyme. Science (New York, NY). 2010;330(6005):831-835. doi:10.1126/science.1191175

17. Li A, Yeo K, Welty D, Rong H. Development of guanfacine extendedrelease dosing strategies in children and adolescents with ADHD using a physiologically based pharmacokinetic model to predict drug-drug interactions with moderate CYP3A4 inhibitors or inducers. Paediatr Drugs. 2018;20(2):181-194. doi:10.1007/s40272-017-0270-0

18. Zhang L, Wei MJ, Zhao CY, Qi HM. Determination of the inhibitory potential of 6 fluoroquinolones on CYP1A2 and CYP2C9 in human liver microsomes. Acta Pharmacol Sin. 2008;29(12):1507-1514. doi:10.1111/j.1745-7254.2008.00908.x

19. Chattopadhyay N, Kanacher T, Casjens M, et al. CYP3A4-mediated effects of rifampicin on the pharmacokinetics of vilaprisan and its UGT1A1-mediated effects on bilirubin glucuronidation in humans. Br J Clin Pharmacol. 2018. doi:10.1111/bcp.13750
20. Pan X, Li Y, Qiu Y, et al. Efficacy and tolerability of first-line triple therapy with levofloxacin and amoxicillin plus esomeprazole or rabeprazole for the eradication of Helicobacter pylori infection and the effect of CYP2C19 genotype: a 1-week, randomized, open-label study in Chinese adults. Clin Ther. 2010;32(12):2003-2011. doi:10.1016/j.clinthera.2010.11.005

21. Paolini M, Poul L, Berjaud C, et al. Nano-sized cytochrome P450 3A4 inhibitors to block hepatic metabolism of docetaxel. Int $J$ Nanomed. 2017;12:5537-5556. doi:10.2147/IJN.S141145

22. Parra-Guillen ZP, Berger PB, Haschke M, et al. Role of cytochrome P450 3A4 and 1A2 phenotyping in patients with advanced non-smallcell lung cancer receiving erlotinib treatment. Basic Clin Pharmacol Toxicol. 2017;121(4):309-315. doi:10.1111/bcpt.12801

23. Chugh R, Wagner T, Griffith KA, et al. Assessment of ifosfamide pharmacokinetics, toxicity, and relation to CYP3A4 activity as measured by the erythromycin breath test in patients with sarcoma. Cancer. 2007;109(11):2315-2322. doi:10.1002/cncr.22669

24. Niwa T, Shiraga T, Hashimoto T, Kagayama A. Effect of cefixime and cefdinir, oral cephalosporins, on cytochrome P450 activities in human hepatic microsomes. Biol Pharm Bull. 2004;27(1):97-99. doi:10.1248/ bpb.27.97

25. Zhou BS, Tsai P, Ker R, et al. Overexpression of transfected human ribonucleotide reductase M2 subunit in human cancer cells enhances their invasive potential. Clin Exp Metastasis. 1998;16(1):43-49. doi:10.1023/A:1006559901771

26. Zhou J, Oliveira P, Li X, Chen Z, Bepler G. Modulation of the ribonucleotide reductase-antimetabolite drug interaction in cancer cell lines. $J$ Nucleic Acids. 2010;2010:597098. doi:10.4061/2010/597098

27. Chen M, Xue X, Wang F, et al. Expression and promoter methylation analysis of ATP-binding cassette genes in pancreatic cancer. Oncol Rep. 2012;27(1):265-269. doi:10.3892/or.2011.1475

28. Guazzelli A, Meysami P, Bakker E, et al. BAP1 status determines the sensitivity of malignant mesothelioma cells to gemcitabine treatment. Int J Mol Sci. 2019;20(2). doi:10.3390/ijms20020429 


\section{Supplementary materials}

Table SI The median progression free survival time (PFS) or the median OS of the patients with biliary tract cancer, pancreatic cancer, sarcoma and other cancers in antibiotics-untreated group and antibiotics-treated group

\begin{tabular}{|c|c|c|c|c|c|c|}
\hline \multirow[t]{2}{*}{ Primary site } & \multicolumn{2}{|c|}{ Median PFS (months) } & \multirow[t]{2}{*}{$P$-value } & \multicolumn{2}{|c|}{ Median OS (months) } & \multirow[t]{2}{*}{$P$-value } \\
\hline & $\begin{array}{l}\text { Antibiotics- } \\
\text { untreated gourp }\end{array}$ & $\begin{array}{l}\text { Antibiotics-treated } \\
\text { group }\end{array}$ & & $\begin{array}{l}\text { Antibiotics- } \\
\text { untreated gourp }\end{array}$ & $\begin{array}{l}\text { Antibiotics-treated } \\
\text { group }\end{array}$ & \\
\hline Biliary tract & 3.4 & 5.4 & 0.1580 & 10.6 & 14.3 & 0.4305 \\
\hline Pancreas & 2.5 & 4.2 & 0.0035 & 6.6 & 13.8 & 0.0020 \\
\hline Sarcoma & 1.9 & 5.1 & 0.2642 & 4.0 & 10.9 & 0.0400 \\
\hline Other cancers & 4.0 & 7.9 & 0.1445 & 9.9 & 10.8 & 0.5997 \\
\hline
\end{tabular}

Notes: Other cancer: CUP, NEC, duodenal cancer, breast cancer, urinary bladder cancer. P-value was calculated using log-rank test.

Table S2 Patient's original data in the present study

\begin{tabular}{|c|c|c|c|c|c|c|c|c|}
\hline \multirow[t]{2}{*}{ Age } & \multirow[t]{2}{*}{ Sex } & \multirow[t]{2}{*}{ Primary site } & \multirow{2}{*}{$\begin{array}{l}\text { Operation } \\
\text { history }\end{array}$} & \multirow{2}{*}{$\begin{array}{l}\text { GEM-containing } \\
\text { regimen }\end{array}$} & \multicolumn{2}{|c|}{ GEM containing regimen } & \multirow{2}{*}{$\begin{array}{l}\text { Date of } \\
\text { death }\end{array}$} & \multirow{2}{*}{$\begin{array}{l}\text { Antibiotics } \\
\text { treatment }\end{array}$} \\
\hline & & & & & $\begin{array}{l}\text { Date of } \\
\text { start }\end{array}$ & $\begin{array}{l}\text { Date of } \\
\text { discontinuation }\end{array}$ & & \\
\hline 69 & Female & Pancreas & No & GC & $11-05-2017$ & $31-08-2018$ & $31-08-2018$ & Carbapenem \\
\hline 63 & Female & Biliary tract & No & GC & $|4-| \mid-2008$ & 0I-05-2009 & 29-07-2009 & Carbapenem \\
\hline 67 & Female & Pancreas & No & GEM & $27-06-2008$ & $24-09-2008$ & $|4-| \mid-2008$ & Carbapenem \\
\hline 54 & Male & Biliary tract & No & GC & $05-07-2017$ & $12-10-2017$ & $31-08-2018$ & Cephem \\
\hline 67 & Male & Biliary tract & No & GC & $15-10-2015$ & $17-12-2015$ & $08-04-2017$ & Cephem \\
\hline 62 & Male & Biliary tract & No & GC & $17-10-2013$ & $02-07-2015$ & $20-08-2015$ & Cephem \\
\hline 69 & Male & Pancreas & No & GC & $25-07-2016$ & $26-09-2016$ & $23-05-2017$ & Cephem \\
\hline 75 & Female & Pancreas & No & GC & $16-06-2015$ & $29-04-2016$ & $24-08-2016$ & Cephem \\
\hline 25 & Male & Sarcoma & No & GD & $16-12-2013$ & $25-05-2017$ & $25-|I-20| 7$ & Cephem \\
\hline 32 & Female & Sarcoma & No & GD & $30-10-2017$ & $16-1 \mid-2017$ & $|2-0|-20 \mid 8$ & Cephem \\
\hline 68 & Male & Biliary tract & No & GEM & $24-11-2015$ & $20-06-2017$ & $31-08-2018$ & Cephem \\
\hline 57 & Male & CUP & No & GEM & $18-08-20 \mid 7$ & $10-11-2017$ & $02-01-2018$ & Cephem \\
\hline 74 & Female & Pancreas & No & GEM & $05-04-2010$ & $02-06-2010$ & $04-06-2010$ & Cephem \\
\hline 76 & Female & Pancreas & No & GEM & $11-12-2006$ & $10-10-2008$ & $11-12-2008$ & Cephem \\
\hline 70 & Female & Pancreas & No & GEM & $24-08-2006$ & $04-12-2008$ & $|2-0|-2009$ & Cephem \\
\hline 49 & Male & Pancreas & No & GEM & $24-07-2014$ & $05-12-20 \mid 4$ & $21-02-2015$ & Cephem \\
\hline 67 & Male & Pancreas & No & GEM & $06-02-2018$ & $27-02-2018$ & $29-04-2018$ & Cephem \\
\hline 66 & Male & Pancreas & No & GEM & $23-03-2017$ & $24-05-2017$ & $26-06-20 \mid 8$ & Cephem \\
\hline 66 & Female & Pancreas & No & GEM & $11-12-2017$ & $31-08-2018$ & $31-08-2018$ & Cephem \\
\hline 68 & Female & Pancreas & No & GEM & $12-05-2017$ & $19-07-2017$ & $24-09-2017$ & Cephem \\
\hline 50 & Male & Pancreas & No & GEM & $30-09-2016$ & $09-12-2016$ & $23-04-2017$ & Cephem \\
\hline 72 & Male & Pancreas & No & GEM & $04-08-2016$ & $15-09-2016$ & $|7-||-20| 6$ & Cephem \\
\hline 84 & Female & Biliary tract & No & $\mathrm{GnP}$ & $27-12-2017$ & $31-08-2018$ & $31-08-2018$ & Cephem \\
\hline 42 & Female & Biliary tract & No & $\mathrm{GnP}$ & $16-03-2016$ & $12-09-2016$ & $0 \mathrm{I}-02-20 \mathrm{I} 7$ & Cephem \\
\hline 62 & Female & Biliary tract & No & GC & $31-05-2016$ & $01-11-2016$ & $0 I-11-2016$ & New quinolone \\
\hline 58 & Male & CUP & No & GC & $26-03-2010$ & $18-1 \mid-2010$ & $|4-02-20| \mid$ & New quinolone \\
\hline 70 & Male & Pancreas & No & GC & $31-10-2015$ & $|2-0|-20 \mid 6$ & $25-03-2016$ & New quinolone \\
\hline 66 & Male & Pancreas & No & GC & $22-08-2014$ & $29-01-2015$ & $19-03-2015$ & New quinolone \\
\hline 68 & Female & Ulinary bladder & No & GC & $|2-09-20| \mid$ & $05-|2-20| 1$ & $16-04-2012$ & New quinolone \\
\hline 36 & Male & Sarcoma & No & GD & $19-06-2015$ & $07-04-2016$ & $07-04-2016$ & $\mathrm{Ne} w$ quinolone \\
\hline 59 & Male & Biliary tract & No & GEM & $30-08-2016$ & $11-04-2017$ & $31-07-2017$ & New quinolone \\
\hline 61 & Male & Biliary tract & No & GEM & $04-06-2012$ & $23-08-2012$ & $25-10-2012$ & New quinolone \\
\hline 58 & Male & Biliary tract & No & GEM & $01-11-2012$ & $3|-0|-20 \mid 3$ & $03-0 \mathrm{I}-20 \mathrm{I} 4$ & New quinolone \\
\hline
\end{tabular}

(Continued) 
Table S2 (Continued).

\begin{tabular}{|c|c|c|c|c|c|c|c|c|}
\hline \multirow{2}{*}{ Age } & \multirow[t]{2}{*}{ Sex } & \multirow[t]{2}{*}{ Primary site } & \multirow{2}{*}{$\begin{array}{l}\text { Operation } \\
\text { history }\end{array}$} & \multirow{2}{*}{$\begin{array}{l}\text { GEM-containing } \\
\text { regimen }\end{array}$} & \multicolumn{2}{|c|}{ GEM containing regimen } & \multirow{2}{*}{$\begin{array}{l}\text { Date of } \\
\text { death }\end{array}$} & \multirow{2}{*}{$\begin{array}{l}\text { Antibiotics } \\
\text { treatment }\end{array}$} \\
\hline & & & & & $\begin{array}{l}\text { Date of } \\
\text { start }\end{array}$ & $\begin{array}{l}\text { Date of } \\
\text { discontinuation }\end{array}$ & & \\
\hline 80 & Female & Biliary tract & No & GEM & $28-02-2011$ & $|6-05-20| \mid$ & $21-10-2011$ & New quinolone \\
\hline 59 & Female & Biliary tract & No & GEM & $31-07-2009$ & $12-1 \mid-2009$ & $0 \mathrm{I}-04-20 \mathrm{II}$ & New quinolone \\
\hline 78 & Male & Biliary tract & No & GEM & $18-09-2007$ & $06-11-2009$ & $10-05-2010$ & New quinolone \\
\hline 54 & Male & Pancreas & No & GEM & $26-03-2015$ & $28-05-2015$ & $16-07-2015$ & New quinolone \\
\hline 72 & Male & Pancreas & No & GEM & $13-02-2015$ & $31-08-2018$ & $31-08-2018$ & New quinolone \\
\hline 64 & Male & Pancreas & No & GEM & $21-02-2011$ & $08-08-2011$ & $29-03-2012$ & New quinolone \\
\hline 66 & Male & Pancreas & No & GEM & $24-09-2010$ & ||$-03-20||$ & $28-05-2011$ & New quinolone \\
\hline 74 & Male & Pancreas & No & GEM & $26-05-2010$ & $05-0 I-20 I I$ & $03-08-2011$ & New quinolone \\
\hline 48 & Male & Pancreas & No & GEM & 06-04-2009 & $21-08-2009$ & $08-05-2010$ & New quinolone \\
\hline 71 & Male & Pancreas & No & GEM & 06-09-2007 & $16-1 \mid-2007$ & $|8-0|-2008$ & New quinolone \\
\hline 70 & Male & Pancreas & No & GEM & $26-05-2006$ & $23-05-2007$ & $05-02-2010$ & New quinolone \\
\hline 69 & Female & Pancreas & No & GEM & $05-10-2006$ & $21-02-2007$ & $23-1 \mid-2007$ & New quinolone \\
\hline 73 & Male & Biliary tract & No & $\mathrm{GnP}$ & $18-05-2015$ & $16-07-2015$ & $11-09-2015$ & New quinolone \\
\hline 77 & Male & Pancreas & No & $\mathrm{GnP}$ & $02-07-2015$ & $26-10-2015$ & $18-06-2016$ & New quinolone \\
\hline 58 & Male & Pancreas & No & $\mathrm{GnP}$ & $|2-| 2-20||$ & $20-01-2012$ & $10-02-2012$ & New quinolone \\
\hline 87 & Female & Pancreas & No & $\mathrm{GnP}$ & $16-02-2018$ & $23-04-2018$ & $19-06-2018$ & New quinolone \\
\hline 70 & Male & Pancreas & No & $\mathrm{GnP}$ & $04-09-2017$ & $24-05-2018$ & $05-07-2018$ & New quinolone \\
\hline 80 & Male & Pancreas & No & $G n P$ & $30-08-2017$ & $18-12-2017$ & $19-02-2018$ & New quinolone \\
\hline 63 & Male & Pancreas & No & GEM & $28-06-2017$ & $21-08-2017$ & $31-08-2018$ & Penicilline \\
\hline 66 & Male & Pancreas & No & GEM & $25-||-20 \mid 4$ & $0 \mathrm{I}-09-2015$ & $01-04-2016$ & $\begin{array}{l}\beta \text {-lactamase } \\
\text { inhibitor }\end{array}$ \\
\hline 61 & Female & Biliary tract & No & GC & $25-08-2014$ & $|8-09-20| 4$ & $25-09-2014$ & None \\
\hline 70 & Male & Biliary tract & No & GC & $24-03-2014$ & $30-05-2014$ & $29-07-2014$ & None \\
\hline 78 & Female & Biliary tract & No & GC & $16-02-2016$ & $13-06-2016$ & $31-07-2016$ & None \\
\hline 71 & Male & Biliary tract & No & GC & $12-08-2016$ & $07-10-2016$ & $05-05-2017$ & None \\
\hline 68 & Female & Biliary tract & No & GC & $|4-07-20| 4$ & $07-10-2014$ & $|5-05-20| 5$ & None \\
\hline 75 & Female & Biliary tract & No & GC & $29-01-2013$ & $12-09-2013$ & $|7-08-20| 4$ & None \\
\hline 58 & Male & Biliary tract & No & GC & $21-01-2013$ & $21-09-2013$ & $06-12-2013$ & None \\
\hline 69 & Female & Biliary tract & No & GC & $10-05-2010$ & $29-06-2010$ & $21-02-2011$ & None \\
\hline 79 & Female & CUP & No & GC & $31-05-2012$ & $24-05-2013$ & $30-09-2013$ & None \\
\hline 50 & Male & NEC & No & GC & $06-10-2014$ & $20-04-2015$ & $27-09-2015$ & None \\
\hline 64 & Female & Biliary tract & No & GCS & $09-10-2015$ & $16-06-2016$ & $06-04-2017$ & None \\
\hline 74 & Male & Biliary tract & No & GCS & $06-01-2016$ & $15-07-2016$ & $12-10-2016$ & None \\
\hline 32 & Male & Sarcoma & No & $\mathrm{GD}$ & $06-03-2017$ & $21-03-2017$ & $04-04-2017$ & None \\
\hline 52 & Female & Sarcoma & No & GD & $31-10-2016$ & $26-12-2016$ & $28-02-2017$ & None \\
\hline 70 & Male & Biliary tract & No & GEM & $10-02-201 \mid$ & $|2-04-20| \mid$ & $28-06-2011$ & None \\
\hline 72 & Female & Biliary tract & No & GEM & 04-09-2008 & $28-10-2008$ & $17-04-2009$ & None \\
\hline 78 & Male & CUP & No & GEM & $27-06-2017$ & $25-07-2017$ & $05-10-2017$ & None \\
\hline 70 & Male & CUP & No & GEM & $14-04-2008$ & $18-08-2008$ & $28-08-2008$ & None \\
\hline 46 & Female & Breast & No & GEM & $10-04-2008$ & $22-05-2008$ & $18-02-2009$ & None \\
\hline 76 & Male & Pancreas & No & GEM & $20-09-2016$ & $05-0 I-2017$ & $13-05-20 \mid 7$ & None \\
\hline 29 & Male & Pancreas & No & GEM & $06-0|-20| 4$ & $28-02-2014$ & $20-06-2014$ & None \\
\hline 80 & Female & Pancreas & No & GEM & $04-09-2014$ & $30-10-2014$ & $14-02-20 \mid 5$ & None \\
\hline 42 & Male & Pancreas & No & GEM & $22-08-2013$ & $15-12-2013$ & $15-12-2013$ & None \\
\hline 61 & Female & Pancreas & No & GEM & $|7-0|-20 \mid 4$ & $|7-09-20| 4$ & $|4-||-20| 4$ & None \\
\hline 65 & Male & Pancreas & No & GEM & $16-05-2013$ & $08-10-2013$ & $02-10-2013$ & None \\
\hline 45 & Female & Pancreas & No & GEM & $23-04-2013$ & $06-06-2013$ & $|2-07-20| 3$ & None \\
\hline 61 & Male & Pancreas & No & GEM & $05-10-2012$ & $06-11-2012$ & $21-11-2012$ & None \\
\hline
\end{tabular}

(Continued) 
Table S2 (Continued).

\begin{tabular}{|c|c|c|c|c|c|c|c|c|}
\hline \multirow[t]{2}{*}{ Age } & \multirow[t]{2}{*}{ Sex } & \multirow[t]{2}{*}{ Primary site } & \multirow{2}{*}{$\begin{array}{l}\text { Operation } \\
\text { history }\end{array}$} & \multirow{2}{*}{$\begin{array}{l}\text { GEM-containing } \\
\text { regimen }\end{array}$} & \multicolumn{2}{|c|}{ GEM containing regimen } & \multirow{2}{*}{$\begin{array}{l}\text { Date of } \\
\text { death }\end{array}$} & \multirow{2}{*}{$\begin{array}{l}\text { Antibiotics } \\
\text { treatment }\end{array}$} \\
\hline & & & & & $\begin{array}{l}\text { Date of } \\
\text { start }\end{array}$ & $\begin{array}{l}\text { Date of } \\
\text { discontinuation }\end{array}$ & & \\
\hline 55 & female & Pancreas & no & GEM & $19-04-2013$ & $|8-06-20| 3$ & $23-09-2013$ & none \\
\hline 69 & male & Pancreas & no & GEM & $|5-0|-20 \mid 3$ & $25-06-2013$ & $05-07-2014$ & none \\
\hline 63 & female & Pancreas & no & GEM & $26-04-2012$ & $0 \mathrm{I}-06-20 \mathrm{I} 2$ & $01-09-2012$ & none \\
\hline 56 & male & Pancreas & no & GEM & $22-09-2011$ & $31-10-2011$ & $|7-||-20| \mid$ & none \\
\hline 52 & male & Pancreas & no & GEM & $13-12-2010$ & ||$-04-20||$ & ||$-04-20||$ & none \\
\hline 69 & male & Pancreas & no & GEM & $12-08-2010$ & $14-10-2010$ & $02-11-2010$ & none \\
\hline 62 & female & Pancreas & no & GEM & $|4-0|-2010$ & $18-02-2010$ & $15-03-2010$ & none \\
\hline 66 & female & Pancreas & no & GEM & $14-12-2009$ & $08-02-2010$ & $01-06-2010$ & none \\
\hline 68 & male & Pancreas & no & GEM & $06-10-2009$ & $10-02-2010$ & $30-11-2010$ & none \\
\hline 73 & male & Pancreas & no & GEM & 14-07-2009 & $13-08-2009$ & $21-11-2009$ & none \\
\hline 69 & male & Pancreas & no & GEM & 07-07-2009 & $27-08-2009$ & $17-10-2009$ & none \\
\hline 74 & female & Pancreas & no & GEM & 02-02-2009 & $23-03-2009$ & 23-03-2009 & none \\
\hline 64 & male & Pancreas & no & GEM & 27-II-2008 & $21-01-2009$ & 24-02-2009 & none \\
\hline 57 & male & Pancreas & no & GEM & $25-||-2008$ & $08-06-2009$ & $17-08-2009$ & none \\
\hline 63 & male & Pancreas & no & GEM & $26-09-2008$ & $07-||-2008$ & II-04-2009 & none \\
\hline 75 & female & Pancreas & no & GEM & $29-05-2008$ & $17-07-2008$ & $10-06-2010$ & none \\
\hline 77 & male & Pancreas & no & GEM & $21-05-2008$ & $04-09-2008$ & 02-06-2009 & none \\
\hline 70 & male & Pancreas & no & GEM & ||$-0 \mid-2008$ & $04-03-2008$ & |4-04-2008 & none \\
\hline 44 & male & Pancreas & no & GEM & $10-10-2007$ & $17-03-2008$ & $23-05-2008$ & none \\
\hline 67 & male & Pancreas & no & GEM & 27-07-2007 & 14-09-2007 & $10-1 \mid-2007$ & none \\
\hline 72 & male & Pancreas & no & GEM & $02-04-2007$ & $28-05-2007$ & $06-08-2007$ & none \\
\hline 60 & male & Pancreas & no & GEM & $27-12-2006$ & $17-08-2007$ & $20-02-2008$ & none \\
\hline 57 & female & Pancreas & no & GEM & $22-11-2006$ & $10-0 \mid-2007$ & $24-04-2007$ & none \\
\hline 72 & female & Pancreas & no & GEM & $30-03-2006$ & $13-06-2006$ & $04-02-2007$ & none \\
\hline 69 & male & Pancreas & no & GEM & $10-08-2012$ & $|I-0|-20 \mid 3$ & $13-04-2013$ & none \\
\hline 63 & female & Pancreas & no & GEM plus elrotinib & $16-09-2010$ & ||$-0|-20| 2$ & $29-02-2012$ & none \\
\hline 71 & male & Pancreas & no & $\mathrm{GnP}$ & $20-02-2018$ & $21-08-2018$ & $31-08-2018$ & none \\
\hline 70 & male & Pancreas & no & $\mathrm{GnP}$ & $28-11-2017$ & $|6-0|-20 \mid 8$ & $27-03-2018$ & none \\
\hline 60 & male & Pancreas & no & $\mathrm{GnP}$ & $02-10-2017$ & $26-02-2018$ & $12-03-2018$ & none \\
\hline 72 & female & Pancreas & no & $\mathrm{GnP}$ & $08-09-2017$ & $16-03-2018$ & $27-05-2018$ & none \\
\hline 61 & male & Pancreas & no & $\mathrm{GnP}$ & $|6-0|-20 \mid 8$ & $21-02-2018$ & $12-05-2018$ & none \\
\hline 68 & male & Pancreas & no & $\mathrm{GnP}$ & $06-09-2017$ & $09-01-2018$ & $26-01-2018$ & none \\
\hline 69 & female & Pancreas & no & $\mathrm{GnP}$ & $21-03-2017$ & $27-04-2017$ & $22-01-2018$ & none \\
\hline 66 & male & Pancreas & no & $\mathrm{GnP}$ & $22-11-2017$ & $31-08-2018$ & $31-08-2018$ & none \\
\hline 65 & female & Pancreas & no & $\mathrm{GnP}$ & $10-03-2017$ & $0 \mathrm{I}-05-20 \mathrm{I7}$ & $28-07-2017$ & none \\
\hline 65 & male & Pancreas & no & $\mathrm{GnP}$ & $31-01-2017$ & $20-07-2017$ & $08-10-2017$ & none \\
\hline 75 & male & Pancreas & no & $\mathrm{GnP}$ & $20-09-2016$ & $3 \mathrm{I}-0 \mathrm{I}-20 \mathrm{I7}$ & $28-03-2017$ & none \\
\hline 75 & female & Pancreas & no & $\mathrm{GnP}$ & $26-09-2016$ & $17-10-2016$ & $15-1 \mid-2016$ & none \\
\hline 73 & female & Pancreas & no & $\mathrm{GnP}$ & $30-08-2016$ & $20-12-2016$ & $20-03-2017$ & none \\
\hline 81 & male & Pancreas & no & $\mathrm{GnP}$ & $28-07-2016$ & $13-10-2016$ & $|8-0|-20 \mid 7$ & none \\
\hline 62 & male & Pancreas & no & $\mathrm{GnP}$ & $03-03-2017$ & $06-04-2017$ & $13-05-2017$ & none \\
\hline 67 & male & Pancreas & no & $\mathrm{GnP}$ & $22-06-2016$ & $21-09-2016$ & $16-12-2016$ & none \\
\hline 77 & female & Pancreas & no & $\mathrm{GnP}$ & $12-05-2015$ & $04-08-2015$ & $03-09-2015$ & none \\
\hline 74 & male & Sarcoma & yes & GD & $14-10-20 \mid 5$ & $29-02-2016$ & $29-08-2018$ & cephem \\
\hline 38 & female & Sarcoma & yes & GD & $11-12-2014$ & $17-06-20 \mid 5$ & $27-08-2015$ & cephem \\
\hline 51 & female & Sarcoma & yes & GD & $13-08-2015$ & $22-02-2016$ & $15-03-2016$ & cephem \\
\hline 58 & female & Pancreas & yes & GEM & $07-06-2017$ & $04-09-2017$ & $|5-||-20| 7$ & cephem \\
\hline 75 & female & Biliary tract & yes & $\mathrm{GnP}$ & $27-09-2017$ & $22-02-2018$ & $04-08-2018$ & cephem \\
\hline
\end{tabular}

(Continued) 
Table S2 (Continued).

\begin{tabular}{|c|c|c|c|c|c|c|c|c|}
\hline \multirow[t]{2}{*}{ Age } & \multirow[t]{2}{*}{ Sex } & \multirow[t]{2}{*}{ Primary site } & \multirow{2}{*}{$\begin{array}{l}\text { Operation } \\
\text { history }\end{array}$} & \multirow{2}{*}{$\begin{array}{l}\text { GEM-containing } \\
\text { regimen }\end{array}$} & \multicolumn{2}{|c|}{ GEM containing regimen } & \multirow{2}{*}{$\begin{array}{l}\text { Date of } \\
\text { death }\end{array}$} & \multirow{2}{*}{$\begin{array}{l}\text { Antibiotics } \\
\text { treatment }\end{array}$} \\
\hline & & & & & $\begin{array}{l}\text { Date of } \\
\text { start }\end{array}$ & $\begin{array}{l}\text { Date of } \\
\text { discontinuation }\end{array}$ & & \\
\hline 78 & male & Pancreas & yes & $\mathrm{GnP}$ & $30-10-2017$ & $|9-0|-20 \mid 8$ & $26-09-2018$ & cephem \\
\hline 50 & male & Pancreas & yes & $\mathrm{GnP}$ & $03-10-2016$ & $21-06-2017$ & $27-03-2018$ & cephem \\
\hline 63 & female & Pancreas & yes & $\mathrm{GnP}$ & $23-07-2015$ & $07-01-2016$ & $30-06-2016$ & cephem \\
\hline 67 & female & Pancreas & yes & $\mathrm{GnP}$ & $18-07-2017$ & $19-03-2018$ & $12-04-2018$ & cephem \\
\hline 59 & female & Pancreas & yes & $\mathrm{GnP}$ & $29-06-2016$ & $26-12-2016$ & $22-01-2017$ & cephem \\
\hline 31 & male & Sarcoma & yes & GD & $19-12-2013$ & $|1-12-20| 4$ & $22-06-2015$ & new quinolone \\
\hline 64 & male & Sarcoma & yes & GD & $|6-04-20| 4$ & $20-06-2014$ & $25-1|-20| 5$ & new quinolone \\
\hline 51 & male & Sarcoma & yes & GD & $10-11-2015$ & $15-12-2015$ & $04-10-2016$ & new quinolone \\
\hline 61 & female & Biliary tract & yes & GEM & $24-11-2016$ & $27-04-2017$ & $|3-0|-20 \mid 8$ & new quinolone \\
\hline 78 & female & Pancreas & yes & GEM & $09-11-2009$ & $26-04-2010$ & $26-07-2010$ & new quinolone \\
\hline 66 & female & Pancreas & yes & GEM plus erlotinib & $20-06-2008$ & $04-||-2008$ & $09-01-2009$ & new quinolone \\
\hline 45 & Fe male & Biliary tract & Yes & $\mathrm{GnP}$ & $08-07-2015$ & $10-06-2016$ & $04-10-2016$ & new Quinolone \\
\hline 46 & Female & Pancreas & Yes & $\mathrm{GnP}$ & $22-03-2013$ & $26-02-20 I 5$ & $31-08-2018$ & New quinolone \\
\hline 63 & Male & Pancreas & Yes & $\mathrm{GnP}$ & $22-08-2013$ & $24-10-2013$ & $06-02-20 \mid 4$ & New quinolone \\
\hline 63 & Male & Pancreas & Yes & $\mathrm{GnP}$ & $30-01-2014$ & $09-04-2014$ & $21-08-2016$ & New quinolone \\
\hline 58 & Male & Pancreas & Yes & $\mathrm{GnP}$ & $10-08-2015$ & $|4-10-20| 5$ & $|4-03-20| 6$ & New quinolone \\
\hline 69 & Male & Pancreas & Yes & $\mathrm{GnP}$ & $07-06-2017$ & $02-02-2018$ & $31-08-2018$ & New quinolone \\
\hline 64 & FEMALE & Biliary tract & Yes & GC & $24-05-2016$ & $08-02-2017$ & $14-12-2017$ & None \\
\hline 62 & Male & Biliary tract & Yes & GC & $25-08-2015$ & $12-04-2016$ & $0 \mathrm{I}-0 \mathrm{I}-20 \mathrm{I} 7$ & None \\
\hline 36 & Male & Biliary tract & Yes & GCS & $21-07-2006$ & $24-03-2008$ & $21-05-2009$ & None \\
\hline 75 & Male & Sarcoma & Yes & GD & $24-08-2012$ & $30-04-2013$ & $03-02-20 \mid 4$ & None \\
\hline 61 & Female & Sarcoma & Yes & GD & $21-07-2017$ & $31-08-2018$ & $31-08-2018$ & None \\
\hline 38 & Male & Sarcoma & Yes & GD & $30-0 I-20 I 5$ & $06-03-20 I 5$ & $27-04-20 I 5$ & None \\
\hline 44 & Male & Sarcoma & Yes & GD & $18-08-20 \mid 6$ & $27-10-2016$ & $16-12-2016$ & None \\
\hline 80 & Female & Sarcoma & yes & GD & $10-02-2014$ & $08-04-20 \mid 4$ & $|2-05-20| 4$ & None \\
\hline 56 & Female & Sarcoma & Yes & GD & $21-02-2017$ & $10-04-2017$ & $09-05-2017$ & None \\
\hline 59 & Male & Sarcoma & Yes & GD & $04-06-2008$ & $05-08-2008$ & $05-09-2008$ & None \\
\hline 70 & Male & Biliary tract & Yes & GEM & $26-03-2007$ & $14-05-2007$ & $06-08-2007$ & None \\
\hline 60 & Male & DK & Yes & GEM & $04-02-2010$ & $27-05-2010$ & $09-09-2010$ & None \\
\hline 66 & Male & DK & Yes & GEM & $26-02-2010$ & $17-09-2010$ & $11-02-2012$ & None \\
\hline 78 & Female & DK & Yes & GEM & $09-02-2006$ & $28-03-2006$ & $02-05-2006$ & None \\
\hline 60 & Male & Pancreas & Yes & GEM & $12-1|-20| 3$ & $28-0|-20| 4$ & $04-06-20 \mid 4$ & None \\
\hline 67 & Female & Pancreas & Yes & GEM & 08-II-20I। & $20-|2-20| \mid$ & $20-|2-20| \mid$ & None \\
\hline 63 & Male & Pancreas & Yes & GEM & 05-II-2009 & $\mid 4-10-2010$ & $|8-0|-20||$ & None \\
\hline 57 & Female & Pancreas & Yes & GEM & $30-09-2009$ & $19-1 \mid-2009$ & $18-06-2010$ & None \\
\hline 62 & Female & Pancreas & Yes & GEM & $20-11-2006$ & $26-0 \mathrm{I}-2007$ & $15-04-2007$ & None \\
\hline $4 I$ & Female & Pancreas & Yes & GEM & $13-04-2012$ & $17-08-2012$ & $09-01-2013$ & None \\
\hline 74 & Male & Pancreas & Yes & $\mathrm{GnP}$ & $12-02-2015$ & $16-12-20 \mid 5$ & $|2-0|-20 \mid 6$ & None \\
\hline 62 & Male & Pancreas & Yes & $\mathrm{GnP}$ & $05-06-2015$ & $14-09-20 \mid 6$ & $20-0|-20| 7$ & None \\
\hline 54 & Male & Pancreas & Yes & $\mathrm{GnP}$ & $10-04-2015$ & $06-07-2015$ & $22-01-2016$ & None \\
\hline 81 & Male & DK & Yes & GEM & $|6-0|-20 \mid 5$ & $03-06-2016$ & $31-08-20 \mid 8$ & $\begin{array}{l}\beta \text {-lactamase } \\
\text { inhibitor }\end{array}$ \\
\hline
\end{tabular}

Abbreviations: CUP, Cancer of unknown primary; NEC, Neuroendocrine carcinoma; GEM, Gemcitabine; GnP, GEM+nabPTX; GC, GEM plus cisplatin; GD, GEM plus docetaxel; GCS, GEM plus cisplatin plus S-I. 


\section{Publish your work in this journal}

Cancer Management and Research is an international, peer-reviewed open access journal focusing on cancer research and the optimal use of preventative and integrated treatment interventions to achieve improved outcomes, enhanced survival and quality of life for the cancer patient.
The manuscript management system is completely online and includes a very quick and fair peer-review system, which is all easy to use. Visit http://www.dovepress.com/testimonials.php to read real quotes from published authors.

Submit your manuscript here: https://www.dovepress.com/cancer-management-and-research-journal 